\title{
Cardiometabolic Syndrome and Increased Risk of Heart Failure
}

\author{
Helene von Bibra ${ }^{1}$ - Walter Paulus ${ }^{2}$ - Martin St. John Sutton ${ }^{3}$
}

Published online: 18 August 2016

(C) The Author(s) 2016. This article is published with open access at Springerlink.com

\begin{abstract}
Approximately $50 \%$ of patients with heart failure have diastolic heart failure (HFPEF) with the major predisposing risk factors age, inactivity, obesity, insulin resistance (IR), type-2 diabetes, and hypertension. The prognosis of HFPEF is comparable to that of systolic heart failure, but without any specific or effective treatment. This review presents a biomathematically corrected diagnostic approach for quantification of diastolic dysfunction (DD) via the age dependency of diastolic function. Pathophysiological mechanisms for DD in the cardiometabolic syndrome (CMS) are mainly based on downstream effects of IR including insufficient myocardial energy supply. The second section discusses therapeutic strategies for the control and therapy of CMS, IR, and the associated DD/HFPEF with a focus on dietary therapy that is independent of weight loss but improves all manifestations of the CMS and reduces cardiovascular risk.
\end{abstract}

Keywords Metabolic syndrome $\cdot \mathrm{HFPEF} \cdot$ Insulin resistance $\cdot$ Diastolic dysfunction $\cdot$ Carbohydrate restriction

This article is part of the Topical Collection on Prevention of Heart Failure

Helene von Bibra

vonbibra@gmx.de

1 Clinic for Endocrinology, Diabetes \& Vascular Medicine, Klinikum Bogenhausen, Städt. Klinikum München GmbH, Munich, Germany

2 Institute for Cardiovascular Research Vrije Universiteit, VU University Medical Center Amsterdam,

Amsterdam, The Netherlands

3 Department of Medicine, Cardiovascular Division, University of Pennsylvania, Philadelphia, PA, USA

$\begin{array}{ll}\text { Abbreviations } \\ \text { CAD } & \text { Coronary artery disease } \\ \text { CMS } & \text { Cardiometabolic syndrome } \\ \text { DD } & \text { Diastolic dysfunction } \\ \text { HDL } & \text { High-density lipoprotein cholesterol } \\ \text { HF } & \text { Heart failure } \\ \text { IR } & \text { Insulin resistance } \\ \text { LDL } & \text { Low-density lipoprotein cholesterol } \\ \text { LV } & \text { Left ventricle } \\ \text { MUFA } & \text { Monounsaturated fatty acids } \\ \text { RAAS } & \text { Renin-angiotensin-aldosterone system } \\ \text { VDLDL } & \text { Very dense LDL particles }\end{array}$

\section{Introduction}

The cardiometabolic syndrome (CMS), also known as insulin resistance (IR) syndrome [1], is a combination of primarily metabolic disorders with IR as the underlying disorder. Its strong link with cardiovascular disease makes CMS the leading cause of morbidity and mortality in the Western world [2, 3].

However, the perilous consequences of CMS are not only coronary artery disease (CAD) but also non-ischemic myocardial dysfunction and heart failure (HF) [4] associated with obesity cardiomyopathy, insulin resistance cardiomyopathy, and diabetes cardiomyopathy [5-7] which suggest that IR is the underlying disorder [8]. Indeed, IR and HF are strongly correlated [9-13] with causal associations between IR and cardiac dysfunction that are observed in the development of IR by genetic and also by environmental factors [14]. In addition, HF predisposes to the development of cardiac and/or systemic IR and type-2-diabetes [15].

The reciprocal relationship between IR and HF is important because it implies therapeutic potential for HFPEF and its 
predecessor diastolic dysfunction (DD): prevalence and prognosis of HFPEF equal those of systolic HF [4, 16-18] but therapeutic studies have been unsuccessful $[19,20 \bullet \cdot, 21 \bullet \cdot]$. This review discusses underlying pathophysiological mechanisms of DD/HF associated with CMS, a potential solution to diagnostic problems and the resulting options for therapy.

\section{CMS and DD/HFPEF}

\section{Background and Prevalence of CMS}

CMS has been defined by the World Health Organization and the National Cholesterol Education Program Adult Treatment Panel III with central obesity and IR as key risks [22••]. The diagnosis requires the presence of any three out of these factors: hyperglycemia (as ultimate result of IR), hypertension, central obesity, dyslipoproteinemia (high triglyceride and/or low high-density lipoprotein (HDL) levels). Age contributes to an increased prevalence of CMS so that an epidemic increase in CMS and its downstream effects on CAD, stroke, and HF imply an ominous impact worldwide [22・•]. Approximately $34 \%$ of the adult US population and about $4 \%$ of the adolescents have CMS that is most frequently driven by obesity. The prevalence of CMS is estimated at $15-25 \%$ in European adults and ranges in the Middle East from $20-37 \%$ in the Gulf States to $28-39 \%$ in Turkey or in urban populations of India [22••].

\section{Prevalence and Clinical Signs of DD/HFPEF}

Over the last two decades, HFPEF has become an increasingly important problem. Prevalence of its preceding abnormality DD is high, ranging from 11 to $27 \%$ in the general adult population, but with a mean of $35 \%$ in individuals with CMS, 12,35 , and $45 \%$ in increasing severity of obesity and 50-70\% in pre-diabetes and in type- 2 diabetes $[8,20 \bullet, 23]$. However, the triggers for the progressive transition into clinical HF remain to be clarified [20••].

The typical clinical symptoms are exertional dyspnea and decreased exercise capacity, leading to reduced quality of life especially in the elderly. If diastolic function at rest is normal, diastolic reserve should be assessed and a 6-min walking test scheduled. In spite of the known risk factors overweight, IR and type-2 diabetes, DD is under diagnosed in these individuals who often conceal their reduced physical performance or have scaled down their activities.

\section{Pathophysiological Mechanisms in CMS Associated Risk for $H F$}

A fundamental principle is known from the ischemic cascade: insufficient energy/oxygen supply initially impairs myocardial diastolic function and only subsequently results in systolic dysfunction [24]. This immediate effect is reversible and without any changes of myocardial structure.

Accordingly, a two-step model appears meaningful for HF and the preceding DD associated with CMS: Its risk factors obesity, IR, type-2 diabetes, dyslipoproteinemia, and hypertension metabolically induce insufficient energy supply, intermittently, repetitively, and reversibly [23, 25, 26•]. In a second step, remodeling mechanisms increase myocardial stiffness and impair late diastolic function. An early and potentially treatable cause such as IR may be differentiated from later remodeling so that therapeutic interventions would not any more target myocardial stiffness alone but focus on earlier metabolic factors in favor of potential prevention.

Overweight impacts on more than half the adult population leading most often to IR. This applies also to cardiology patients and implies metabolic constraints for myocardial energy supply in addition to the individual cardiac disease [8, 25, 27]. Recently, IR was confirmed as one of the three top risk factors for DD in non-diabetic individuals and the top risk factor in type-2 diabetes $[21 \bullet \bullet]$.

\section{Insulin Signaling Links to Cardiac Function}

Cardiac IR may develop independently of systemic IR. More often and subsequent to prolonged or excessive overnutrition, systemic IR relevantly contributes to secondary cardiac IR with oxidative stress and neurohumoral/sympathetic and/or cytokine imbalance. Two different pathways of insulin signaling impact on cardiac function [13]:

- The phosphatidylinositol-3 kinase/protein kinase B (Akt) signaling pathway elicits mainly beneficial metabolic responses. The downstream mechanisms include the activation of Akt and atypical protein kinase-C isoforms mediating the following reactions: Glucose transporter type- 4 (Glut4) translocation leading to glucose uptake in myocardial/muscular tissue, nitric oxide mediated coronary dilatation, metabolic substrate flexibility and energy homeostasis, and balanced calcium handling.

- The mitogen-activated protein kinase (MAPK) signaling pathway elicits growth factor-like responses that contribute to growth and remodeling responses such as myocellular hypertrophy, cardiac fibrosis, impaired myocardial-endothelial signaling and death of myocardial and endothelial cells.

The resultant complex and reciprocal metabolic mechanisms involve altered substrate use and decreased myocardial ATP generation, endothelium induced dysregulation of myocardial perfusion and impaired calcium handling that lead to DD in its early stage (Fig. 1) before inflammatory and cytokine abnormalities, lipo- and glucotoxicity, oxidative stress from reactive oxygen species, upregulation of the renin- 


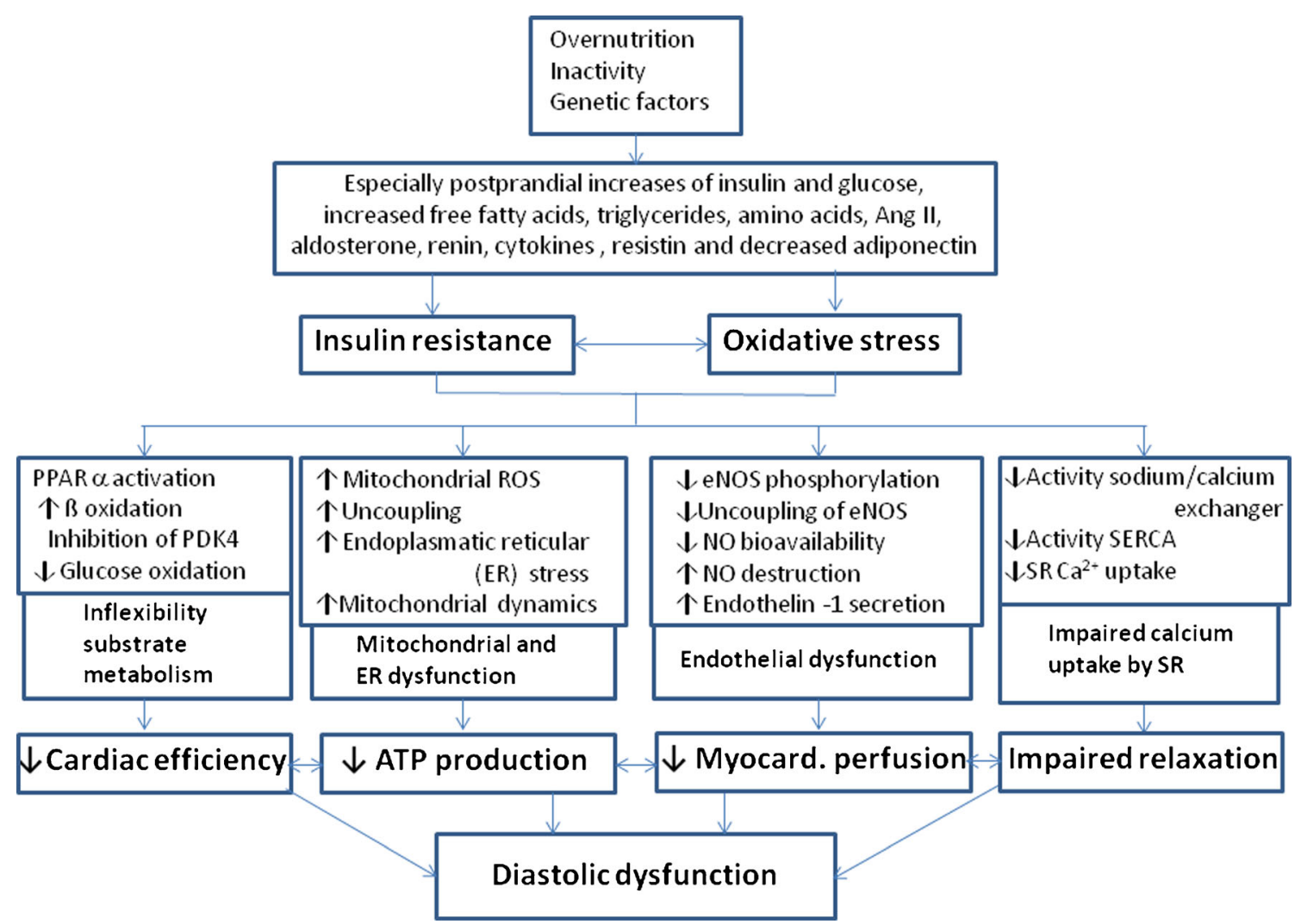

Fig. 1 Molecular mechanisms in cardiac insulin resistance via overnutrition and impaired insulin signaling leading to repetitive intermittent lack of energy in the early stage of cardiac dysfunction that is DD. The progression to remodeling processes including myocellular hypertrophy, altered titin, collagen and fibrosis metabolism, accumulation of triglycrides, and/or advanced glycemic end products and also the

angiotensin-aldosterone (RAAS) and sympathetic nervous system induce remodeling processes. These imply myocellular hypertrophy, fibrosis, collagen, and titin modifications and accumulation of triglycerides and/or advanced glycemic end products leading to cell damage and further deterioration of DD and also contractile function. The specific impact and sequence of these mechanisms for the development of HF in man remain to be clarified [13, 14, 19, 20••, $27,28]$.

\section{Diagnostic Criteria for the Risk of HF in CMS}

HFPEF/DD is a functional diagnosis with many different comorbidities. The major risk factors are age and CMS that include obesity, IR, type-2 diabetes, and hypertension, furthermore CAD, anemia, chronic obstructive pulmonary disease, sleep apnea, renal disease, and rare congenital abnormalities. Given the epidemic of CMS, early accurate diagnosis of DD is of pivotal importance for the development of preventive strategies. In contrast to HFREF and systolic dysfunction, there is no consensus as to how to quantify $\operatorname{DD}[8,20 \bullet \bullet, 25]$. This problem activation of the renin-angiotensin and sympathetic nervous system will lead to further myocardial cell damage and, potentially, to contractile dysfunction and/or heart failure. Ang II angiotensin II, ROS reactive oxygen species, $E R$ endoplasmatic reticulum, eNOS endothelial nitric oxide synthase, SERCA sarcoplasmic endoplasmic reticulum Ca2+ - ATPase 2a, $S R$ sarcoplasmatic reticulum (modified from [13])

contributes to the lack of clinically relevant results in therapeutic studies [16, 20••, 26•].

The European and American guidelines define DD as an abnormal LV filling pressure that may be estimated noninvasively by $\mathrm{E} / \mathrm{E}^{\prime}>15$. For the intermediate range $8-15$, additional parameters of potential DD involve mainly increased left atrial volume or LV mass, a diminished mitral inflow ratio E/A and/or biomarkers [17]. These echocardiographic metrics were considered partly non-sensitive or inconclusive [21••, 29]. A single criterion for quantification of myocardial diastolic function is not available to assess DD although tissue Doppler derived E' has prognostic potential and also correlates with exercise capacity [8, 30••, 31].

A biomathematical approach may solve this diagnostic problem: age is such a dominant determinant of diastolic myocardial function that it accounts for $88 \%$ predictability of diastolic function but only $39 \%$ of systolic function [21••]. Accordingly, DD needs to be defined as the deficit between the E' and an age-related normal value from healthy individ-

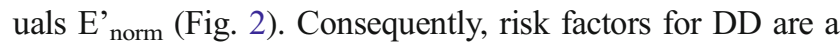
function of this deficit $E^{\prime}$ norm $-E$ '. This approach avoids the biomathematical error of defining risk factors that also depend 
Non-Diabetic Controls

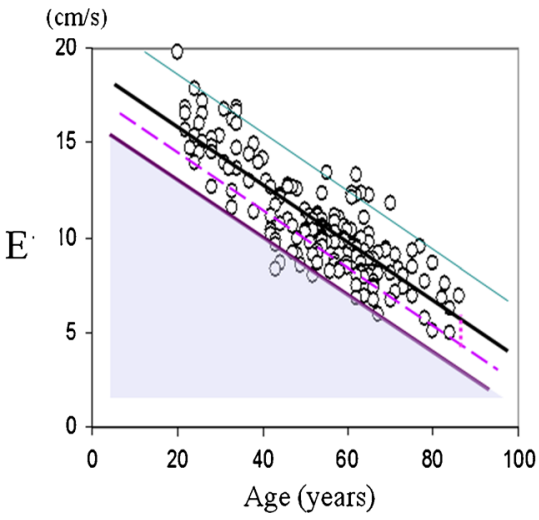

Fig. 2 Diastolic myocardial function E' as function of age in nondiabetic controls (left) and type-2 diabetes (right) with the regression line (black) and upper and lower tolerance intervals (purple and green) from healthy controls. Diastolic dysfunction is defined as difference $E^{\prime}-E_{\text {norm }}$

heavily on age. Instead, the central importance of metabolic abnormality, i.e. IR, is revealed $[21 \bullet \bullet]$.

\section{Non-Pharmacological Therapeutic Strategies for CMS}

The epidemic of CMS is mainly caused by environmental factors such as inactivity and the availability of cheap and "fast" foods rich in energy from starches and fat. The single major cause of poor health in cardiology patients is poor diet.

However, doctors receive very little training in healthy nutrition in spite of reviews that actually remove the ban from fat and demonstrate the risks of high carbohydrate intake [32••, $33 \bullet \bullet, 34]$.

\section{Dietary approaches}

In CMS, dietary approaches aim for these issues: (1) weight normalization and maintenance long-term, (2) elimination of postprandial glucose and insulin peaks without weight loss, and (3) reduction of the risk factors dyslipoproteinemia and hypertension.

(1) Weight Reduction and Maintenance:

A relevant reduction of weight may abolish IR/ hyperinsulinemia by the reduction of ectopic fat accumulation and improve all manifestations of the CMS [35]. It is achieved rather by diet than by exercise only [36]. The fundamental hypocaloric nutrition renders various diets suitable:

- Low-fat nutrition has been traditionally recommended as restriction of fat to about $60 \mathrm{~g}$ daily and high carbohydrate ingestion [34, 37•]. Via a daily energy deficit of $500 \mathrm{kcal}$, mean weight loss may be $3-4 \mathrm{~kg}$ within 6 months followed commonly by a regain in weight $[38,39]$. There is no
Type-2 Diabetes

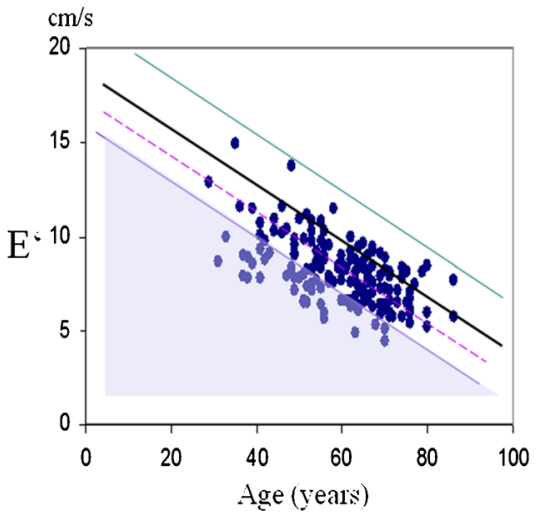

on the regression line $>2.86$ (shaded triangle) and risk for diastolic dysfunction if the deficit is $>50 \%$ of this cut off level (between the dashed line and the lower tolerance line) (modified from [21••])

evidence for more effective weight loss compared to other hypocaloric diets [40] but evidence for a long-term increase of overweight and cardiovascular disease $[32 \bullet$, $41,42]$.

- Carbohydrate restricted diets show superior weight loss by about $3 \mathrm{~kg}$ within 6 months if compared to low-fat diets $[43,44]$ with some subsequent regain, so that weight loss at 12 months is $1-2 \mathrm{~kg}$ greater but not significant [44].

- Carbohydrate modification implies a reduction of glycemic index (GI) and glycemic load (GL) (table) resulting effectively in weight loss $[45 \cdot \bullet, 46,47]$. An example is the LOGI (low glycemic and insulinemic) method [48] based on recommendations for obesity therapy at the Boston children's hospital [49] with avoidance of refined starch and saccharose products and preference for food with low GI (vegetable, legumes, and whole grain products) minimizing postprandial glucose and insulin peaks [46]. Metaanalysis demonstrates superior weight loss within 6 months for diets with reduced GI and/or GL including the Mediterranean diet [46, 47]. Additionally, the cardiovascular risk factors dyslipoproteinemia, hypertension $[30 \bullet, 37 \bullet, 50,51]$, and IR are improved [30••, 52].

Only $20 \%$ of subjects maintain weight loss long-term. Attainment of this goal may be supported by two measures:

- A decrease of energy density to $<125 \mathrm{kcal} / 100 \mathrm{~g}$ of consumed food is recommended given population based values of $\geq 160 \mathrm{kcal} / 100 \mathrm{~g}$ [34]. This aim requires to consume more food high in water and fibers (salad, vegetable, fruit, fish, milk/milk products, and lean meat) and less high-energy food (fast food rich in fat and sugar, customary bakery products, sugared lemonades, and fruit juices) [53]. An advisable low-energy meal may be a salad with 
breast of turkey and olive oil dressing in spite of its $40 \%$ content in fat [48].

- Improved satiety is achieved by increasing water and fiber content of food and protein intake to a total of $30 \%$ (about $2 \mathrm{~g} / \mathrm{kg}$ body weight) [47, 54]. In healthy people, no harm has been shown for such a moderate increase of protein intake but advantages for maintaining weight loss [55].

(2) GL Restriction for Normalizing IR Without Weight Loss:

In the course of CMS, long-term normalization of weight is often unrealistic. Hence, dietary strategies are preferable that normalize postprandial insulin and glucose peaks and IR independent of weight loss in these high risk individuals [56].

Postprandial hyperglycemia subsequent to a carbohydrate meal is common in individuals with IR. The associated fluctuations of glucose and insulin are known cardiovascular risk factors $[57,58]$ depending mainly on two mechanisms:

- Reduced insulin sensitivity, i.e., IR leads to higher postprandial glucose peaks in these compared to insulin sensitive individuals $[48,59]$. The more insulin resistant a person is, the more insulin is required to keep blood glucose within normal limits rendering the normalization of hyperinsulinemia/IR an important therapeutic target.

- Postprandial glucose values are directly determined by the quality, i.e. GI, and quantity, i.e. GL, of the consumed carbohydrates. Their specific reduction provides a practical tool to prevent postprandial hyperglycemia and hyperinsulinemia (Table 1) [57, 60]. In lean healthy individuals, $37 \%$ of the postprandial glucose levels are determined by GI, but $90 \%$ by GL that contributes also to a greater extent to atherogenic dyslipoproteinemia [32••, 61].

GL restriction has several advantages: (a) Preclusion of hunger attacks between meals by hyperinsulinemia with relative hypoglycemia, (b) unlimited access to other macronutrients inducing improved satiety and maintenance of weight loss [55], (c) a reduction of cardiovascular risk and IR independent of weight loss $[30 \bullet \bullet, 45 \bullet \cdot, 51,52,56,62,63]$, and (d) a reduction or abolishment of antidiabetic medication in line with preventing hypoglycemia $[30 \bullet, 45 \bullet \cdot]$. This return to a healthier life increases patients' compliance and minimizes the potentially ominous side effects of antidiabetics [64]. A GL restriction is now implemented in the guidelines for type-2 diabetes [65]. Substantial evidence supports its therapeutic use as safe and immediately effective $[32 \bullet \bullet, 37 \bullet, 43,50,63,66$, 67].

(3) Reduction of Dyslipoproteinemia and Hypertension: High triglyceride, VDLDL, LDL, and low HDL cholesterol levels characterize the atherogenic dyslipoproteinemia in
Table 1 Table of glycemic index (GI) and glycemic load (GL) in commonly used foods containing relevant amounts of carbohydrates

\begin{tabular}{|c|c|c|c|c|}
\hline Food & $\begin{array}{l}\mathrm{GI} / \\
100 \mathrm{~g}\end{array}$ & $\begin{array}{l}\text { Serving } \\
\text { Size }(g)\end{array}$ & $\begin{array}{l}\text { Available } \\
\text { Carbohydrates } \\
\text { g/serving size }\end{array}$ & GL \\
\hline Spaghetti, white boiled & $44 \pm 3$ & 180 & 48 & 21 \\
\hline Spaghetti, full grain boiled & $37 \pm 5$ & 180 & 42 & 16 \\
\hline Cornflakes & $81 \pm 3$ & 60 & 52 & 42 \\
\hline Baguette & $95 \pm 15$ & 60 & 30 & 30 \\
\hline Wheat bread & $70 \pm 0$ & 60 & 28 & 20 \\
\hline Rye kernel bread & $50 \pm 4$ & 60 & 24 & 12 \\
\hline Rice, long grain boiled & $56 \pm 2$ & 150 & 41 & 23 \\
\hline Rice, brown boiled & $55 \pm 5$ & 150 & 33 & 18 \\
\hline Potatoes baked & $85 \pm 12$ & 150 & 30 & 26 \\
\hline Potatoes cooked & $56 \pm 101$ & 150 & $17-26$ & $\begin{array}{r}11- \\
18\end{array}$ \\
\hline Potato chips & $54 \pm 3$ & 90 & 63 & 33 \\
\hline Peas & $35 \pm 4$ & 150 & 15 & 5 \\
\hline $\begin{array}{l}\text { Carots (raw and } \\
\text { boiled) }\end{array}$ & $47 \pm 16$ & 150 & 12 & 6 \\
\hline Kidneybeans (canned) & 52 & 150 & 17 & 9 \\
\hline Lentils, green boiled & $30 \pm 4$ & 150 & 17 & 5 \\
\hline Peanuts & $14 \pm 8$ & 50 & 6 & 1 \\
\hline Bananas (raw) & $52 \pm 4$ & 120 & 24 & 12 \\
\hline Grapes white (raw) & $46 \pm 3$ & 120 & 18 & 8 \\
\hline Mango & $51 \pm 3$ & 120 & 17 & 8 \\
\hline Watermelon & $72 \pm 13$ & 120 & 6 & 4 \\
\hline Apples & $38 \pm 2$ & 120 & 15 & 6 \\
\hline Oranges & $42 \pm 3$ & 120 & 11 & 5 \\
\hline Peaches & $42 \pm 14$ & 120 & 11 & 5 \\
\hline Strawberry (raw) & $40 \pm 7$ & 120 & 3 & 1 \\
\hline Milk (full fat) & $27 \pm 4$ & 250 & 12 & 3 \\
\hline Yoghurt (full fat) & $36 \pm 4$ & 200 & 9 & 3 \\
\hline Ice cream & $61 \pm 7$ & 50 & 13 & 8 \\
\hline
\end{tabular}

Modified from [60]

CMS that may be improved by macronutrient modification without weight loss $[34,68]$. Low-fat/high-carbohydrate nutrition effectively reduced LDL but deteriorated triglycerides, VDLDL, and HDL [69]. However, a partial replacement of carbohydrate content with an isocaloric amount of fat (preferably monounsaturated fatty acids (MUFA)) improved all factors of dyslipoproteinemia, confirmed in meta-analysis for healthy and diabetic individuals and the Mediterranean diet $[44,68,70,71]$. Supplementation with omega-3-fatty acids may reduce serum triglycerides [72]. Given the risks of nonalcoholic fatty-liver disease in CMS, alcohol consumption should be low-to-moderate [34].

CMS associated hypertension may be treated by weight loss alone. Other options imply a restriction of sodium to about $4 \mathrm{~g}$ daily, or increases in the intake of potassium, 
calcium, long-chain omega-3 fatty acids and protein, in particular vegetable protein [34]. The Omni Heart Study (Optimal Macronutrient Intake Trial for Heart Health) successfully combined these factors subsequent to the DASH diet (dietary approach to stop hypertension) promoting the intake of vegetable, nuts, fruit, full grain, and lean milk products, poultry and fish [73, 74]. This macronutrient modification is consistent with the observed lowering of blood pressure via normalized hyperinsulinemia by GI/GL restriction $[30 \bullet \bullet, 50,62]$ also in the higher-fat DASH diet promoting full-fat dairy [75].

Of relevance, this nutritional modification with restricted carbohydrate intake and more protein and fat intake - referring particularly to vegetable protein and vegetable oil-is safe and lowers the risks for CAD and mortality [76].

\section{Exercise Training in CMS}

A recent meta-analysis confirmed that exercise has beneficial effects on triglycerides, HDL, apolipoprotein A1, leptin, interleukin-18, fibrinogen, and angiotensin II but not for C-reactive protein, interleukin- 6 , tumor necrosis factor $\alpha$, or adiponectin [77]. The beneficial effects on insulin metabolism were substantially enlarged in the presence of CMS risk factors. Both moderate and vigorous exercise training improved cardiometabolic health [77].

Aerobic exercise is recommended for the sedentary beginner as walking [78] or biking with incrementally increasing duration and intensity along the measure of keeping a conversation ongoing. Resistance training has also shown beneficial effects on $\mathrm{HbA1c}$, fat mass, and systolic blood pressure but not on triglycerides, cholesterol levels, and diastolic blood pressure in patients with dysglycemia [79]. A measurable reduction of mortality was found even for modest incremental increases of fitness and training [80]. Further studies are needed to explore the apparent superiority of aerobic training for risk factors in CMS and the interaction with nutritionally deteriorated IR.

\section{Bariatric Surgery}

Bariatric surgery implies gastric banding, sleeve gastrectomy, the Roux-en-Y gastric bypass, and biliopancreatic diversion techniques. Recently, the indication was extended from severe obesity to mild-to-moderate obesity combined with type-2 diabetes or CMS. Bariatric surgery may induce remission of type- 2 diabetes in about $60 \%$ after 6 years and $36 \%$ after 10 years [81]. The immediate effects of glucose lowering stem from the sudden negative calorie balance and the increase of GLP-1 response on food delivery into the small intestine. Long-term effects are based on the excess weight loss with its increase in insulin sensitivity. The prevalence of CMS may be reduced by $60-95 \%$ in 1-3 years [82] and that of hypertension and the other risk factors by $>30 \%$ [22••].

\section{Pharmacological Agents}

From the three recent options for overweight treatment, orlistat, sibutramine, and rimonabant, only orlistat is currently available. It modestly lowers weight associated with improvements in LDL, fasting insulin, blood pressure, and potentially diastolic function $[22 \bullet \bullet]$.

The pharmacological therapy of hypertension, of dyslipoproteinemia, and of diabetes is well established. Its discussion would be beyond the scope of this review that is focused on new developments in association with CMS and the risk of HF.

\section{Non-Pharmacologic Therapeutic Strategies for DD/HFPEF}

Given the different cardiovascular comorbidities with their specific treatments, therapeutic studies in DD/HFPEF need specifically selected participants. The uncertainty about the triggers for a progress from DD to HFPEF makes the effective treatment of DD an important preventive intervention so that the discussion of DD and HFPEF treatment strategies is combined.

By now, promising alternative strategies exist for treating the underlying CMS. The respective clinical studies are rare for several reasons. Firstly, HF, DD, and cardiovascular risks are not routinely assessed in randomized trials on CMS. Secondly, studies on life style changes most commonly do not asses DD. Thirdly, research on nutrition and exercise is difficult to finance being not in the promotional scientific program of pharmaceutical industry whereas the beneficial potential for the affected patients may save millions of dollars annually for the public health systems.

\section{Dietary Approaches}

In obese type- 2 diabetics, weight loss nutrition ( $460 \mathrm{kcal}$ daily for 4 months) improved DD and myocardial triglyceride content [83]. In severe obesity, low GI diet vs. bariatric surgery both induced relevant weight loss and improved LV mass and DD after 1 year [84]. Moderate aerobic training was the exercise intervention for a comparison of low-fat/high-carbohydrate nutrition $(1800 \mathrm{kcal})$ with an isocaloric GL restricted diet in obese type-2 diabetics (HbAlc 7,1\%) [30••] achieving similar reductions in weight, total cholesterol, and $\mathrm{HbAlc}$ after 3 weeks. Only GL restriction led to significant improvements of postprandial glucose and insulin levels, IR, triglycerides, blood pressure, diastolic function, and exercise capacity, i.e. all factors of CMS. In the parallel group on low-fat diet, these metabolic and functional parameters remained unchanged but improved in the subsequent crossover design with GL restriction for 2 weeks [30••]. These results were obtained in spite of a more than $50 \%$ reduction 
of the antidiabetic medical therapy with GL restriction necessary to avoid hypoglycemia vs. $16 \%$ with low-fat nutrition. This major reduction of antidiabetic medications implies that modification/restriction of carbohydrate intake is a causal therapy of CMS and its associated myocardial dysfunction [26•, 85]. Evidence confirms such a major reduction of antidiabetic medication subsequent to GL restriction in type- 2 and type-1 diabetes both for oral antidiabetics and for insulin [45••, 50, 85].

Regarding dietary effects on HFPEF in CMS, a case report in an obese type- 2 diabetic on insulin therapy with IR and a recent onset of HFPEF showed reversal of DD by GL restriction within 3 weeks but without relevant weight loss [66]. A study in "hypertensive" HFPEF in 13 individuals with treated hypertension and stable HFPEF demonstrated improvements of blood pressure, DD, and HFPEF symptoms by the lowsodium DASH diet [86] that implies also lowered GI/GL [72]. Considering that the study participants had a mean BMI of $35.5 \pm 7.9 \mathrm{~kg} / \mathrm{m}^{2}$ and that $43 \%$ had type- 2 diabetes, the etiology of HFPEF might have been regarded to relate both to IR and hypertensive heart disease but this issue was not discussed in line with no information provided regarding weight loss.

Summarizing, relevant weight loss or normalization of IR induced by GL restriction or bariatric surgery unequivocally improved DD [30••, 66, 83, 84, 86].

\section{Exercise Training}

In spite of the accepted beneficial effects of exercise for cardiovascular risk factors in CMS, the effects on the associated DD are ambiguous. Notably, the respective study designs for exercise in obese type- 2 diabetics have maintained the traditional low-fat/high-carbohydrate nutrition [87, 88]. Their ambiguous outcome fits the results of the low-fat vs. GL restriction dietary arm in spite of moderate aerobic training as discussed above [30••]. A possible mechanism behind this apparent discrepancy of exercise effects has recently been shown: A single carbohydrate meal may worsen DD in type2 diabetics and non-diabetic individuals [89•]. This suggests that the beneficial effects of exercise on DD may be neutralized by nutritional deterioration in IR.

Improved physical performance and DD by exercise training have been shown in HFPEF patients with overweight (BMI $31 \pm 5 \mathrm{~kg} / \mathrm{m}^{2}$ ) and additional $\geq 1$ risk factors [31] but this report, like so many exercise studies, does not report the nutritional recommendations during the intervention.

A recent meta-analysis of six studies concluded that exercise in HFPEF does not improve DD in spite of improvements in cardiorespiratory fitness and quality of life [90]. However, the echocardiographic parameters used to assess DD relied on $\mathrm{E} / \mathrm{A}$ and/or deceleration time that imply bimodal changes in the course of diastolic disease rendering the respective interpretation of interventional results difficult.
Summarizing these exercise studies, the assessment of diastolic function should use tissue Doppler derived and quantifiable methods of assessing DD [21••]. This diagnostic method should be applied for assessing the potential of IR normalization for the treatment/reversal of DD via both specific exercise and nutritional interventions.

\section{Pharmaceutical Therapy}

Given the diverse comorbidities of DD/HFPEF, the respective treatment approach needs to primarily address this underlying problem. Concerning CAD, arterial hypertension, and peripheral vascular disease, the respective treatments are well established and beyond the scope of this review. Instead, discussion presents developments in the therapy of IR and type-2 diabetes with potential for improving DD/HF.

\section{Insulin Resistance}

The biguanide metformin improves hepatic and peripheral IR and LV diastolic function in patients with type-2 diabetes [91]. It affects translocation of glucose transporters Glut1 and Glut4, prevents hyperglycemia induced abnormalities in relaxation by reducing intracellular $\mathrm{Ca}$ transients, and maintains metabolic flexibility [22••].

Glitazones had been designed to increase insulin sensitivity. However, the associated effect on renal collecting ducts is fluid retention so that use of these drugs was not recommended for patients with (advanced) HF. In type-2 diabetics without cardiac disease, DD was improved by pioglitazone [92].

Within the GPL-1 analogues, liraglutide in the LEADER trial [93] has just been announced to effectively improve CV deaths but not systolic HF whereas lixisenatide did not alter cardiovascular events and HF hospitalization in patients with type-2 diabetes and acute coronary syndrome [94]. Studies on $\mathrm{DD} / \mathrm{HF}$ in diabetes are underway.

Data for the protective action of $D D P-4$ inhibitors are inconclusive. Sitagliptin was shown to potentially improve DD [95]. In a large retrospective study, the use of DPP-4 inhibitors compared with sulphonylureas was associated with a reduced risk of hospitalization for HF whereas an earlier comparison of saxagliptin with placebo had demonstrated an increased risk for HF hospitalization [96].

The recent sodium/glucose cotransporter-2 (SGLT2) inhibitor empagliflozin lowers blood glucose irrespective of beta-cell function and IR by blocking glucose reabsorption in the proximal renal tubulus with subsequent excretion of abundant glucose. This elimination precludes protective metabolic mechanisms against hyperglycemic and insulinemic peaks. The EMPA-REG outcome study data showed a decrease of $\mathrm{CV}$ deaths and an improved hospitalization rate with HF [97•]. Studies 
on DD and HF in patients without and with type-2 diabetes are underway.

\section{Glucose-Lowering Antidiabetic Therapy}

Awareness has grown for the risks from hypoglycemic events and/or the simultaneous use of several antidiabetics [64]. Nevertheless, evidence shows that glucose control does matter in patients with diabetes [98], especially for the risk of DD/HF from postprandial dysmetabolism and IR [27, 99•]. Besides metformin, insulin therapy may be protective: multiple daily injection (MDI) vs. mixed insulin regimen and the use of analogue MDI vs. human insulin MDI regimen have shown specifically lowered postprandial glucose levels and improved myocardial function and perfusion [8, 99•, 100].

Unfortunately, the assessment of postprandial metabolism is ignored in most evidence creating studies. Furthermore, the different stages of IR deserve consideration for tailoring therapeutic strategies. Given the nutritional induction of postprandial hyperglycemia in IR and type-2 diabetes, carbohydrate restriction remains the most appropriate antidiabetic therapy.

Summarizing, patients with significant hyperglycemia benefit most from immediate insulin-based strategies that improve especially postprandial glucose, and those patients with stable glucose control should receive immediate carbohydrate restriction combined with meticulous adaptation of their individual antidiabetic regimen.

\section{Conclusion: Risk of DD/HFPEF in CMS}

The diagnostic design of respective therapeutical studies in overt HFPEF or for its prevention is substantially and biomathematically improved by the new approach for quantification of DD via the age dependence of diastolic function [21••] and should apply a homogenous selection of CMS individuals in order to create the necessary statistical evidence.

Patients with CMS and DD have as underlying key mechanism depleted cardiac energetic reserve caused by IR. Given unequivocous clinical studies on the dietary treatment of DD/ HFPEF and the consistent evidence from dietary treatment of the underlying CMS, causal therapy is a normalization of insulin sensitivity by the therapeutic use of diets with modified macronutrient composition: increased vegetables, fruits and salads, reduced GL in favor of full grain products, and liberalization of fat in favor of MUFA/PUFA associated with an aerobic exercise program.

\section{Compliance with Ethical Standards}

Conflict of Interest Helene von Bibra, Walter Paulus, and Martin St. John Sutton declare that they have no conflict of interest.

Human and Animal Rights and Informed Consent This article does not contain any studies with human or animal subjects performed by any of the authors.

Open Access This article is distributed under the terms of the Creative Commons Attribution 4.0 International License (http:// creativecommons.org/licenses/by/4.0/), which permits unrestricted use, distribution, and reproduction in any medium, provided you give appropriate credit to the original author(s) and the source, provide a link to the Creative Commons license, and indicate if changes were made.

\section{References}

Papers of particular interest, published recently, have been highlighted as:

- Of importance

• Of major importance

1. Reaven GM. Insulin resistance: the link between obesity and cardiovascular disease. Med Clin North Am. 2011;95:875-92.

2. Grundy SM, Cleeman JI, Daniels SR, Donato KA, Eckel RH, et al. Diagnosis and management of the metabolic syndrome: an American Heart Association /National Heart, Lung and Blood Institute Scientific Statement. Circulation. 2005;112:2735-52.

3. Alberti KG, Eckel RH, Grundy SM, et al. International Diabetes Federation Task Force on Epidemiology and Prevention; National Heart Lung and Blood Institute; American Heart Association; World Heart Federation; International Atherosclerosis Society; International Association for the Study of Obesity. Harmonizing the metabolic syndrome: a joint interim statement of the International Diabetes Federation Task Force on Epidemiology and Prevention; National Heart Lung and Blood Institute; American Heart Association; World Heart Federation; International Atherosclerosis Society and International Association for the Study of Obesity. Circulation. 2009;120: 1640-5.

4. Redfield MM, Jacobsen SJ, Burnett Jr JC, Mahoney DW, Bailey KR, Rodeheffer RJ. Burden of systolic and diastolic ventricular dysfunction in the community: appreciating the scope of the heart failure epidemic. JAMA. 2003;289:1994-202.

5. Wong C, Marwick TH. Obesity cardiomyopathy: pathogenesis and pathophysiology. Nat Clin Pract Cardiovasc Med. 2007;4: 436-43.

6. Witteles RM, Fowler MB. Insulin-resistant cardiomyopathy. Clinical evidence, mechanisms and treatment options. J Am Coll Cardiol. 2008;51:93-102.

7. Boudina S, Dale Abel E. Diabetic cardiomyopathy revisited. Circulation. 2007;115:3213-23.

8. von Bibra H, St. John Sutton M. DD in diabetes and metabolic syndrome - diagnostic and prognostic potential. Diabetologia. 2010;53:1033-45. 
9. Thrainsdottir IS, Aspelund T, Gudnason V, et al. Increasing glucose levels and BMI predict future heart failure. Experience from the Reykjavik study. Eur J Heart Fail. 2007;9:1051-7.

10. Vardeny O, Gupta DK, Claggett B, Burke S, Shah A, Loehr L, et al. Insulin resistance and incident heart failure: the ARIC study (Atherosclerosis Risk in Communities). JACC Heart Fail. 2013;1: $531-6$.

11. Banerjee D, Biggs ML, Mercer L, Mukamal K, Kaplan R, Barzilay J, et al. Insulin resistance and incident heart failure; cardiovascular health study. Circ Heart Fail. 2013;6:364-70.

12. Ingelsson E, Sundstrom J, Arnlov J, et al. Insulin resistance and risk of congestive heart failure. JAMA. 2005;294:334-41.

13. Aroor $\mathrm{AR}$, Mandavia $\mathrm{CH}$, Sowers JR. Insulin resistance and heart failure: molecular mechanisms. Heart Fail Clin. 2012;8:609-17.

14. Ashrafian H, Frenneaux MP, Opie LH. Metabolic mechanisms in heart failure. Circulation. 2007;116:434-8.

15. Mamas MA, Deaton C, Rutter MK, et al. Impaired glucose tolerance and insulin resistance in heart failure: underrecognized and undertreated? J Card Fail. 2010;16:761-8.

16. Borlaug BA, Paulus WJ. Heart failure preserved ejection fraction: pathophysiology, diagnosis and treatment. Eur Heart J. 2011;32: 670-9.

17. Paulus WJ, Tschope C, Sanderson JE, et al. How to diagnose diastolic heart failure: a consensus statement on the diagnosis of heart failure with normal ejection fraction by the heart failure and echocardiography associations of the european society of cardiology. Eur Heart J. 2007;28:2539-50.

18. Schocken DD, Benjamin EJ, Fonarow GC, et al. Prevention of heart failure: a scientific statement of the American heart association councils. Circulation. 2008;117:2544-65.

19. Paulus $\mathrm{W}$, Tschöpe C. A novel paradigm for heart failure with preserved ejection fraction: comorbidities drive myocardial dysfunction and remodeling through coronary microvascular endothelial inflammation. J Am Coll Cardiol. 2013;62:263-71.

20.• Wan SH, Vogel MW, Chen HH. Pre-clinical diastolic dysfunction. J Am Coll Cardiol. 2014;63:407-16. Thorough epidemiologic and etiologic discussions of DD, the preceding abnormality of HFPEF.

21.• von Bibra H, Paulus W, St John Sutton M, Leclerque C, Schuster T, Schumm-Draeger PM. Quantification of DD via the age dependence of diastolic function - impact of insulin resistance with and without type 2 diabetes. IJC. 2015;182:368-74. The dominant dependence of age on diastolic function has important biomathematical consequences: dysfunction can be quantified by the difference of the actually measured $E$ ' to the age related normal value from a regression equation derived from healthy individuals. Furthermore, risk factors need to be assessed in relation to this difference, so that the error is avoided to "identify" risk factors that also heavily depend on age.

22.• Kelli HM, Kassas I, Lattouf O. Cardio metabolic syndrome: a global epidemic. J Diabet Metab. 2015;6:513-26. Broad epidemiologic insight into the cardiometabolic syndrome.

23. von Bibra H, Paulus W. Diastolic dysfunction - echocardiographic detection, etiology and therapy. Kardiologe. 2016;10:47-55.

24. Serizawa T, Vogel WM, Apstein CS, Grossman W. Comparison of acute alterations in left ventricular relaxation and diastolic chamber stiffness induced by hypoxia and ischemia. J Clin Invest. 1980;68:91-102.

25. Phan TT, Abozguia K, Shivu G, et al. Heart failure with preserved ejection fraction is characterized by dynamic impairment of active relaxation and contraction of the left ventricle on exercise and associated with myocardial energy deficiency. J Am Coll Cardiol. 2009;54:4002-9.

26. Fontes-Carvalho R, Ladeiras-Lopes R, Bettencourt P, et al. DD in the diabetic continuum: association with insulin resistance, metabolic syndrome and type 2 diabetes. Cardiovasc Diabetol. 2015;14:4-12. This review resets diastolic dysfunction in diabetes from a glucose centered view into the close link to insulin resistance, i.e. the key problem of metabolic syndrome.

27. Hwang YC, Jee JH, Kang M, et al. Metabolic syndrome and insulin resistance are associated with abnormal left ventricular diastolic function and structure independent of blood pressure and fasting plasma glucose level. Int J Cardiol. 2012;179:107-11.

28. Ritchie R. Evidence for a causal role of oxidative stress in the myocardial complications of insulin resistance. Heart Lung Circ. 2009;18:11-8.

29. Lam CS. HFpEF: invasive solution to diagnostic confusion? J Am Coll Cardiol. 2010;55:1711-2.

30.• von Bibra H, Wulf G, St John Sutton M, Schuster T, Pfützner A, Heilmeyer P. Low-carbohydrate/high-protein diet improves diastolic cardiac function and the metabolic syndrome in overweight-obese patients with type 2 diabetes. IJC Metab Endoc. 2014;2:11-8. This hypothesis creating study with partial cross-over design assesses the therapeutic effects of either a traditional low-fat or a low carbohydrate diet, i.e. low GI and GL, on cardiac function and cardiovascular risk factors and glucose/insulin metabolism in obese type-2-diabetics, given an identical moderate aerobic training in any dietary intervention.

31. Edelmann F, Gelbrich G, Düngen HD, et al. Exercise training improves exercise capacity and diastolic function in patients with heart failure with preserved ejection fraction. J Am Coll Cardiol. 2011;58:1781-92.

32.• Siri-Tarino PW, Chiu S, Bergeron N, Krauss RM. Saturated fats versus polyunsaturated fats versus carbohydrates for cardiovascular disease prevention and treatment. Annu Rev Nutr. 2015;35: 517-43. The effects of saturated fatty acids on cardiovascular risk factors are profoundly modulated by the macronutrients that replace them, meaning that replacement by PUFAs has shown beneficial effects but replacement with carbohydrates did not or did worsen cardiovascular risk.

33.• Mozaffarian D, Ludwig DS. The 2015 US dietary guidelines: lifting the ban on total dietary fat. JAMA. 2015;313:2421-2. Based on the Dietary Guidelines Advisory Committee's recent recommendations, the ban on total dietary fat is lifted.

34. Ströhle A, Worm N. Metabolisches syndrom. Pathophysiologische grundlagen und rationale empfehlungen zur ernährungstherapie. Deutsche Apotheker Zeitung. 2012:152:50-67.

35. Reaven GM. The insulin resistance syndrome: definition and dietary approaches to treatment. Annu Rev Nutr. 2005;25:391-406.

36. Franz MJ, Vanwormer JJ, Crain AL, et al. Weight-loss outcomes: a systematic review and meta-analysis of weight-loss clinical trials with a minimum 1-year follow-up. J Am Diet Assoc. 2007;107: 1755-67.

37. Ajala O, English P, Pinkney J. Systematic review and meta-analysis of different dietary approaches to the management of type 2 diabetes. Am J Clin Nutr. 2013;97:505-16. A meta-analysis of 20 RCTs about the effects of various diets on glycemic control, lipids and weight loss in type 2 diabetes demonstrating that low-carbohydrate, low GI, Mediterranean and high protein diets effectively improve various markers of cardiovascular risk. 
38. Astrup A, Grunwald GK, Melanson EL, et al. The role of low fat diets in body weight control: a meta-analysis of ad libidum dietary intervention studies. Intern Obes Relat Metab Disord. 2000;24: 1545-52.

39. Howard BV, Manson JE, Stefanick MI, et al. Low-fat dietary pattern and weight change over 7 years: the womens health initiative dietary modification trial. Jama. 2006;295:39-49.

40. Pirozzo S, Summerbell C, Cameron C, et al. Should we recommend low-fat diets for obesity? Obes Rev. 2003;4:83-90.

41. Marantz PR, Bird ED, Alderman MH. A call for higher standards of evidence for dietary guidelines. Am J Prev Med. 2008;34:234 40.

42. Yang Q, Zhang Z, Gregg EW, et al. Added sugar intake and cardiovascular diseases mortality among US adults. JAMA Intern Med. 2014;174:516-24.

43. Hession M, Rolland C, Kulkarni U, et al. Systematic review of randomized controlled trials of low-carbohydrate vs. low-fat/lowcalorie diets in the management of obesity and its comorbidities. Obes Rev. 2009;10:36-50.

44. Nordmann AJ, Nordmann A, Briel M, et al. Effects of lowcarbohydrate vs. low-fat diets on weight loss and cardiovascular risk factors: a meta-analysis of randomized controlled trials. Arch Int Med. 2006;166:285-93.

45.• Feinstein RD, Pogozelski WK, Astrup A, et al. Dietary carbohydrate restriction as the first approach in diabetes management: critical review and evidence base. Nutrition. 2015;31:11-3. A prudent discussion about the present need for a reappraisal of dietary guidelines given the epidemic of obesity, diabetes and cardiovascular risk. The benefits of carbohydrate restriction are presented in $\mathbf{1 2}$ points of evidence as opposed to the conjectural concerns about the respective efficacy and safety.

46. Shikany JM, Desmond R, Mc Cubrey R, et al. Meta-analysis of studies of a specific delivery mode for a modified carbohydrate diet. J Hum Nutr Diet. 2011;24:525-35.

47. Thomas De, Elliott EJ, Baur L. Low gycemic index or low glycemic load diets for overweight and obesity. Cochrane Database Syst Rev. 2007;(3):CD005105

48. Worm N. Ernährungsempfehlungen beim metabolischen syndrom. Schweiz Z Ernährungsmed. 2007;5:29-34.

49. Ebbeling CB, Leidig MM, Sinclair KB, et al. Effects of an ad libitum low-glycemic load diet on cardiovascular disease risk factors in obese young adults. Am J Clin Nutr. 2005;81:976-82.

50. Accurso A, Bernstein RK, Dahlqvist A, et al. Dietary carbohydrate restriction in type 2 diabetes mellitus and metabolic syndrome: time for a critical appraisal. Nutr Metab. 2008;5:9-17.

51. Frisch S, Zittermann A, Berthold HK, et al. A randomized controlled trial on the efficacy of carbohydrate-reduced or fat-reduced diets in patients attending a telemedically guided weight loss program. Cardiovasc Diabetol. 2009;8:36-45.

52. Pereira MA, Swain J, Goldfine AB, et al. L low-glycemic load diet on resting energy expenditure and heart disease risk factors during weight loss. JAMA. 2004;292:2482-90.

53. Mendoza JA, Drewnowski A, Chistakis DJ. Dietary energy density is associated with obesity and the metabolic syndrome in U.S. adults. Diabetes Care. 2007;30:974-9.

54. Abete I, Astrup A, Martinez JA, et al. Obesity and the metabolic syndrome: role of different dietary macronutrient distribution patterns and specific nutritional components on weight loss and maintenance. Nutr Rev. 2010;68:214-31.

55. Larsen TM, Dalskov SM, van Baak M, et al. For the diets obesity and genes (Diogenes) project. Diets with high or low protein content and glycemic index for weight-loss maintenance. $\mathrm{N}$ Eng J Med. 2010;363:2102-13.

56. Santos FL, Esteves SS, da Costa PA, et al. Systematic review and meta-analysis of the effects of low carbohydrate diets on cardiovascular risk factors. Ob Rev. 2012;13:1048-66.
57. Ceriello A, Colagiuri S. International diabetes federation guideline for management of postmeal glucose: a review of recommendations. Diab Med. 2008;25:1151-6.

58. Monnier L, Mas E, Ginet C, et al. Activation of oxidative stress by acute glucose fluctuations compared with sustained chronic hyperglycemia in patients with type 2 diabetes. JAMA. 2006;295: 1681-7.

59. Hwalla N, Shakera L, Torbaya N, et al. Postprandial glycemic and insulinemic responses to high-carbohydrate vs. high-protein meals in obese normoglycemic subjects with varied insulin sensitivity. Nutr Res. 2005;25:535-48.

60. Foster-Powell K, Holt SH, Brand-Miller JC. International table of glycemic index and glycemic load values: 2002. Am J Clin Nutr. 2002;76:56.

61. Micha R, Nelson M. Glycemic index and glycemic load used in combination to characterize metabolic responses of mixed meals in healthy, lean, young adults. J Am Coll Nutr. 2011;30:113-25.

62. Te Morenga LA, Howatson AJ, Jones RM, et al. Dietary sugars and cardiometabolic risk: systemativ review and meta-analysis of randomized controlled trials of the effects on blood pressure and lipids. Am J Clin Nutr. 2014;100:165-79.

63. Dong JY, Zhang JH, Wang P, et al. Meta-analysis of dietary glycemic load and glycemic index in relation to risk of coronary heart disease. Am J Cardiol. 2012;109:1608-13.

64. Gerstein HC, Me M, Byington RP, et al. Effects of intensive glucose lowering in type 2 diabetes. N Engl J Med. 2008;358:254559.

65. Executive Summary. Standards of medical care in diabetes2014. Diabetes Care. 2014;37(1):120-43.

66. Heilmeyer P, von Bibra H. Diastolic heart failure treated by diet. Dtsch Med Wochenschr. 2016;141:121-4.

67. Joslin Diabetes Center \& Clinic. Clinical nutrition guideline for overweight and obese adults with type 2 diabetes or those at higher risk for developing type 2 diabetes. http://www.joslin.org/bin from cms/Nutrition Guidelines-8.22.11\%281\%29.pdf

68. Kodama S, Saito K, Tanaka S, et al. Influence of fat and carbohydrate proportions on the metabolic profile in patients with type 2 diabetes: a meta-analysis. Diabetes Care. 2009;32:959-65.

69. Mensink RP, Zock PL, Kester AD, et al. Effects of dietary fatty acids and carbohydrates on the ratio of serum total to HDL cholesterol and on serum lipids and apolipoproteins: a meta-analysis of 60 controlled trials. Am J Clin Nutr. 2003;77:1146-55.

70. Krauss RM, Blanche RJ, Rawlings RS, et al. Separate effects of reduced carbohydrate intake and weight loss on atherogenic dyslipidemia. Am J Clin Nutr. 2006;83:1025-31.

71. Cao Y, Mauger DJ, Pelkman CL, et al. Effects of moderate (MF) versus lower fat (LF) diets on lipids and lipoproteins: a metaanalysis of clinical trials in subjects with and without diabetes. J Clin Lipidol. 2009;3:19-32.

72. Eslick GD, Howe PR, Smith C, et al. Benefits of fish oil supplementation in hyperlipidemia: a systematic review and meta-analysis. Int J Cardiol. 2009;136:4-16.

73. Appel LJ, Sacks FM, Carey VJ, et al. Effects of protein, nonsaturated fat, and carbohydrate intake on blood pressure and serum lipids: results of the Omni-heart randomized trial. JAMA. 2005;294:2455-64.

74. Appel LJ, Moore TJ, Obarzanek E, et al. A clinical trial of the effects of dietary patterns on blood pressure: DASH Collaborative Research Group. N Engl J Med. 1997;336:1117-24.

75. Chiu S, Bergeron N, Williams PT, et al. Comparison of the DASH (Dietary Approaches to Stop Hypertension) diet and a higher-fat DASH diet on blood pressure and lipids and lipoproteins: a randomized controlled trial. Am J Clin Nutr. 2016. doi:10.3945 /ajen.115.123281. 
76. Fung TT, van Dam RM, Hankinson SE, et al. Low-carbohydrate diets and all-cause and cause-specific mortality: two cohort studies. Ann Intern Med. 2010;153:289-98.

77. Lin X, Zhang X, Guo J, et al. Effects of exercise training on cardiorespiratory fitness and biomarkers of cardiometabolic health: a systematic review and meta-analysis of randomized controlled trials. J Am Heart Assoc. 2015;4:e02014. doi:10.1161 /JAHA.115.002014.

78. Hanson S, Jones A. Is there evidence that walking groups have health benefits? a systematic review and meta-analysis. Br J Sports Med. 2015;0:1-7.

79. Strasser B, Strasser B, Siebert U, Schobersberger W. Resistance training in the treatment of the metabolic syndrome: a systematic review and meta-analysis of the effect of resistance training on metabolic clustering in patients with abnormal glucose metabolism. Sports Med. 2010;40:397-E.

80. Wen C, Wai JP, Tsai MK, et al. Minimum amount of physical activity for reduced mortality and extended life expectancy: a prospective cohort. Lancet. 2011;378:1244-53.

81. Mechanik JI, Youdim A, Jones DB, et al. Clinical practice guidelines for the perioperative nutritional, metabolic, and nonsurgical support of the bariatric surgery patient-2013 update: cosponsored by american association of clinical endocrinologists, the obesity society, and American society for metabolic \& bariatric surgery\$. Surg Obes Relat Dis. 2013;9:159-91.

82. Batsis JA, Romera-Corral A, Collazo-Clavell ML, Sarr MG, Somers VK, Lopez-Jimenez F. Effect of bariatric surgery on the metabolic syndrome: a population-based, long-term controlled study. Mayo Clin Proc. 2008;83:897-907.

83. Hammer S, Snel M, Lamb HJ, et al. Prolonged caloric restriction in obese patients with type 2 diabetes mellitus decreases myocardial triglyceride content and improves myocardial function. J Am Coll Cardiol. 2008;52:1006-12.

84. Rider OJ, Francis JM, Ali MK, et al. Beneficial cardiovascular effects of bariatric surgical and dietary weight loss in obesity. $\mathrm{J}$ Am Coll Cardiol. 2009;54:718-26.

85. von Bibra H, St. John Sutton M. Impact of diabetes on postinfarction heart failure and left ventricular remodelling. Curr Heart Fail Rep. 2011;8:242-51.

86. Hummel SL, Seymour EM, Brook RD, et al. Low-sodium DASH diet improves diastolic function and ventricular-arterial coupling in hypertensive heart failure with preserved ejection fraction. Circ Heart Fail. 2013;6:1165-71.

87. Hordern MD, Coombes JS, Cooney LM, et al. Effects of exercise intervention on myocardial function in type 2 diabetes. Heart. 2008;95:1343-9.

88. Kosmala W, O'Moore-Sullivan T, Plaksej R, et al. Improvement of left ventricular function by lifestyle intervention in obesity: contributions of weight loss and reduced insulin resistance. Diabetologia. 2009;52:2306-11.

89. von Bibra H, St John Sutton M, Schuster T, Ceriello A, Siegmund T, Schumm-Draeger PM. Oxidative stress after a carbohydrate meal contributes to the deterioration of diastolic cardiac function in non-hypertensive insulin-treated patients with moderately well controlled type 2 diabetes. Horm Met Res. 2013;45:449-55. This prospective interventional study compared the effects of a single carbohydrate meal on oxidative stress and cardiac function in type-2-diabetes and non-diabetic controls, demonstrating an association of increased oxidative stress with decreased diastolic function postpranidally especially in diabetic individuals.

90. Pandey S, Parashar A, Kumbhani DJ, et al. Exercise training in patients with heart failure and preserved ejection fraction. Metaanalysis of randomized control trials. Circ Heart Fail. 2015;8:33-40.

91. Anderson C, Sogaard P, Hoffmann S, et al. Metformin is associated with improved left ventricular diastolic function measured by tissue Doppler imaging in patients with diabetes. Eur J Endocrin. 2010;163:593-9.

92. van der Meer RW, Rijzewijk LJ, de Jong HW, et al. Pioglitazone improves cardiac function and alters myocardial substrate metabolism without affecting cardiac triglyceride accumulation and high-energy phosphate metabolism in patients with wellcontrolled type 2 diabetes mellitus. Circulation. 2009;119:206977.

93. Marso SP, Daniels GH, Brown-Frandsen K, et al. for the LEADER steering committee on behalf of the LEADER investigators. Liraglutide and cardiovascular outcomes in type 2 diabetes. N Engl J Med. 2016;375:311-22.

94. Pfeffer NA, Claggett B, Diaz R, et al. Lixisenatide in patients with type 2 diabetes and acute coronary syndrome. N Engl J Med. 2015;373:2247-57.

95. Oe H, Nakamura K, Kihara H, et al. Comparison of sitagliptin and voglibose on left ventricular DD in patients with type 2 diabetes: results of the 3D trial. Cardiovasc Diabet. 2015;14:83-96.

96. Fadini GP, Avogaro A, Degli Esposti L, et al. Risk of hospitalization for heart failure in patients with type 2 diabetes newly treated with DPP-4 inhibitors or other oral glucose-lowering medications: a retrospective registry study on 127,555 patients from the Nationwide OsMed Health-DB Database. Eur Heart J. 2015;36: 2454-62.

97. Fitchett D, Zinman B, Wanner C et al., EMPA REG OUTCOME Investigators.Heart Failure Outcomes with Empagliflozin in Patients with Type 2 Diabetes at High Cardiovascular Risk: Results of the EMPA-REG OUTCOME® Trial. Eur Heart J. 2016;37:1526-34. In patients with type 2 diabetes and high cardiovascular risk, the most recently developed SGLT2 inhibitor empagliflozin reduced heart failure hospitalization and cardiovascular death, with a consistent benefit in patients with and without baseline heart failure as compared to placebo

98. De Caterina R, Madonna R, Sourij H, et al. Glycemic control in acute coronary syndromes: prognostic value and therapeutic options. Eur Heart J. 2010;31:1557-64.

99. Von Bibra H, Siegmund T*, Kingreen I, Riemer M, Schuster T, Schumm-Draeger PM. Analogue insulin in multiple daily injection therapy of type 2 diabetes improves postprandial glucose control compared to human insulin, associated with beneficial effects on cardiac function - a randomized controlled long-term study. Cardiovasc Diabetol. 2016;15:7-17. The improvement of postprandial glucose matters for the improvement of diastolic dysfunction and may be achieved in insulin dependent type 2 diabetes by MDI with analogue insulins as compared to MDI with human insulins.

100. Scognamiglio R, Negut C, de Kreutzenberg S, Tiengo A, Avogaro A. Effects of different insulin regimens on postprandial myocardial perfusion defects in type 2 diabetic patients. Diabetes Care. 2006;29:95-100. 